\title{
Calibration and validation of water vapour lidar measurements from Eureka, Nunavut, using radiosondes and the Atmospheric Chemistry Experiment Fourier Transform Spectrometer
}

\author{
A. Moss ${ }^{1}$, R. J. Sica ${ }^{1}$, E. McCullough ${ }^{1}$, K. Strawbridge ${ }^{2}$, K. Walker ${ }^{3}$, and J. Drummond ${ }^{4}$ \\ ${ }^{1}$ Department of Physics and Astronomy, The University of Western Ontario, London, Canada \\ ${ }^{2}$ Centre for Atmospheric Research Experiments, Environment Canada, Egbert, Canada \\ ${ }^{3}$ Department of Physics, University of Toronto, Toronto, Canada \\ ${ }^{4}$ Department of Physics and Atmospheric Science, Dalhousie University, Halifax, Canada \\ Correspondence to: R. J. Sica (sica@uwo.ca)
}

Received: 7 August 2012 - Published in Atmos. Meas. Tech. Discuss.: 17 August 2012

Revised: 9 February 2013 - Accepted: 1 March 2013 - Published: 15 March 2013

\begin{abstract}
The Canadian Network for the Detection of Atmospheric Change and Environment Canada DIAL lidar located at the Polar Environment Atmospheric Research Laboratory (PEARL) in Eureka, Nunavut, has been upgraded to measure water vapour mixing ratio profiles. The lidar is capable of measuring water vapour in the dry Arctic atmosphere up to the tropopause region. Measurements were obtained in the February to March polar sunrise during 2007, 2008 and 2009 as part of the Canadian Arctic ACE (Atmospheric Chemistry Experiment) Validation Campaign. Before such measurements can be used to address important questions in understanding dynamics and chemistry, the lidar measurements must be calibrated against an independent determination of water vapour. Here, radiosonde measurements of relative humidity have been used to empirically calibrate the lidar measurements. It was found that the calibration varied significantly between each year's campaign. However, the calibration of the lidar during an individual polar sunrise campaign agrees on average with the local radiosonde measurements to better than $12 \%$. To independently validate the calibration of the lidar derived from the radiosondes, comparisons are made between the calibrated lidar measurements and water vapour measurements from the ACE satellite-borne Fourier Transform Spectrometer (ACE-FTS). The comparisons between the lidar and satellite-borne spectrometer for both a campaign average and single overpasses show favourable agreement between the two instruments and help validate the lidar's calibration. The 39 nights of high-Arctic water
\end{abstract}

vapour measurements obtained offer the most detailed high spatial-temporal resolution measurement set available for understanding this time of transition from the long polar night to polar day.

\section{Introduction}

There are many open questions with regard to water vapour's role in climate and weather. An area of high concern is water vapour's role in Earth's radiative balance, including the various feedbacks involved, both positive (increases in longwave absorption of solar radiation) and negative (increases in water vapour leading to increases in cloud formation causing cooling due to albedo changes). These feedbacks give rise to important yet unresolved questions related to water vapour and its changes in response to a changing climate. Such questions can be addressed with improved measurement capabilities such as those provided by the Canadian Network for the Detection of Atmospheric Change (CANDAC) instrumentation situated at the Polar Environment Atmospheric Research Laboratory (PEARL) in Eureka, Nunavut $\left(80.2^{\circ} \mathrm{N}\right.$, $\left.86.4^{\circ} \mathrm{W}\right)$.

The goal of this study is to determine a calibration for the CANDAC-Environment Canada Stratospheric Differential Absorption Lidar (DIAL; henceforth the CEC Lidar) water vapour mixing ratio measurements by comparison to water vapour measurements made by locally launched radiosondes. 
Details of the instrument are given in the next section. The CEC Lidar must be calibrated to convert its photocount profiles into water vapor mixing ratio profiles. The procedure and results of this calibration are presented in Sect. 3. In Sect. 4 comparisons are made to measurements from the Atmospheric Chemistry Experiment Fourier Transform Spectrometer (ACE-FTS). Trends in the water vapour mixing ratio during polar sunrise for 3 seasons of measurements are given in Sect. 5.

\section{The CEC Lidar}

The PEARL at Eureka consists of three laboratories, two of which are located near the weather station at sea level. The third is the Ridge Laboratory, located $610 \mathrm{~m}$ above sea level about $18 \mathrm{~km}$ from the weather station. The CEC Lidar was installed there in 1992.

Polar sunrise occurs at Eureka in late February. It is an exciting time to take measurements, as sunlight interacts with the atmosphere for the first time after months of darkness. Polar sunrise is a time of rapid variations in atmospheric chemistry and dynamics resulting in significant changes in ozone over a period of a few days. Polar sunrise also gives an opportunity to make coincident measurements with instruments aboard the ACE satellite, which has good coverage above Eureka at this time of year for its solar occultation measurements.

The CEC Lidar was initially designed as a stratospheric ozone DIAL. The lidar was then upgraded to include Raman capabilities for measuring molecular nitrogen to help reduce the effect of aerosols on the ozone measurements. A diagram of the system is given in Pal et al. (1996), as well as a detailed description of the system. Recently, the capability of the lidar was enhanced again with the addition of a water vapour Raman channel. However, for useful scientific measurements of water vapour a calibration is necessary and will be developed in the next section. The CEC Lidar can only operate during darkness and at this time is not capable of measurements when the Sun is near or above the horizon. This distinction is important as night and day extend for several months during the solstice periods at Eureka.

\subsection{Transmitter and receiver}

The transmitter used for these measurements is a Lumonics EXCIMER-600 XeCl laser with an unstable resonator cavity. The laser output is $100 \mathrm{~mJ}$ per pulse at $308 \mathrm{~nm}$, and has a divergence of $0.4 \mathrm{mrad}$. A second output wavelength is generated by stimulated Raman Stokes scattering in a hydrogen gas cell, converting a portion of the $308 \mathrm{~nm}$ beam to $353 \mathrm{~nm}$, producing $10 \mathrm{~mJ}$ per pulse. The pulse repetition rate of the laser is $300 \mathrm{~Hz}$, with pulse lengths of $13 \mathrm{~ns}$. The output beam is expanded and re-collimated using a concave mirror reducing the divergence to $0.2 \mathrm{mrad}$. Finally, the output beam is reflected off a flat steering mirror to ensure its vertical path to the atmosphere is aligned with the field-of-view of the receiver.

The receiver is a $1 \mathrm{~m}$ diameter Newtonian telescope. This telescope collects light backscattered from the atmosphere at all wavelengths, including the 385 and $406 \mathrm{~nm}$ used for water vapour. A secondary mirror is used to direct light to the detection system. Further details concerning the basic system and in particular its ozone measurement capabilities are given by Carswell et al. (1991).

\subsection{Data acquisition system}

Detection of signals at the wavelengths of interest requires filtering of the collected light. Light in the required wavelength band is selected using dichroic beam-splitting mirrors, which reflect below a certain wavelength but allow the remaining light to be transmitted. Using these dichroic mirrors it is possible to separate the light into elastic returns at 308 and $353 \mathrm{~nm}$ and inelastic returns at 332 and $385 \mathrm{~nm}$ (from nitrogen Raman scattering), as well as $406 \mathrm{~nm}$ (from water vapour Raman scattering). The light passes through narrow band interference filters before being focussed onto one of five photomultiplier tubes. For the elastic channels a mechanical chopper and neutral density filters are used to attempt to keep the counting electronics linear over the required count-rate range.

The photomultiplier tubes are used in photon counting mode so they are capable of detecting the weak signals from the upper atmosphere as well as the faint Raman signals from water vapour. Photon counting is triggered by an optical pickoff linked to the timing unit which gives a reference for each outgoing laser pulse. In the counting unit, pulses accumulate in bins of fixed duration (and therefore fixed altitude range from the lidar), allowing for a vertical backscatter intensity profile to be obtained. For water vapour mixing ratio measurements, the best combination of channels resulting in the highest signal-to-noise ratio returns are the 385 and $406 \mathrm{~nm}$ channels, which will be used in the subsequent analysis.

Tests for signal-induced noise (SIN) on the Eureka system were performed by Steinbrecht (1994). His results showed that at $308 \mathrm{~nm}$ the SIN is more important than any nonlinearities in the counting system. He also showed that SIN at $353 \mathrm{~nm}$ was small (but significant), and negligible at longer wavelengths. Since this study uses measurements at 385 and $406 \mathrm{~nm}$, SIN effects will be even smaller.

\section{Calibration from radiosonde measurements}

\subsection{The water vapour retrieval}

Melfi et al. (1969) showed that the ratio of the return from the 2 Raman channels at 385 and $406 \mathrm{~nm}$ is proportional to the water vapour mixing ratio. The constant of proportionality 
which relates the water vapour mixing ratio, $w(z)$, to the ratio of the nitrogen $\left(S_{N_{2}}\right)$ and water vapour photocounts $\left(S_{\mathrm{H}_{2} \mathrm{O}}\right)$ is given by Whiteman et al. (1992) as

$w(z)=C_{w} \Delta_{\tau}^{w}\left(z_{0}, z\right) \cdot \frac{S_{\mathrm{H}_{2} \mathrm{O}}}{S_{\mathrm{N}_{2}}}$,

where the calibration constant, $C_{w}$, is

$C_{w}=\frac{k_{\mathrm{N}_{2}}}{k_{\mathrm{H}_{2} \mathrm{O}}} \cdot \frac{\sigma_{\mathrm{N}_{2}}}{\sigma_{\mathrm{H}_{2} \mathrm{O}}} \cdot \frac{M_{\mathrm{H}_{2} \mathrm{O}}}{M_{\mathrm{dry}}} \cdot \frac{n_{\mathrm{N}_{2}}}{n_{\text {dry }}}$

and the ratio of atmospheric transmissions is

$\Delta_{\tau}^{w}\left(z_{0}, z\right)=\frac{\tau\left(\lambda_{\mathrm{N}}, z_{0}, z\right)}{\tau\left(\lambda_{\mathrm{H}}, z_{0}, z\right)}$.

The ratio of the transmissions is both height and wavelength dependent. In order to estimate the transmission at the two Raman wavelengths, the MODTRAN model (Anderson et al., 1993) is used assuming clear-sky conditions. This ratio is only weakly height dependent in clear-sky conditions, particularly over the region of CEC Lidar water vapour measurements.

The calibration constant depends on several factors, including the ratio of the detector quantum efficiencies $(k)$, the ratio of the Raman cross sections $(\sigma)$ and the ratio of the molecular mass $(M)$ of water vapour to nitrogen. The final term is the proportion of nitrogen in dry air $\left(n_{N_{2}} / n_{\text {dry }}\right)$, allowing $w(z)$ to be expressed as a mixing ratio by assuming the ratio of nitrogen to oxygen in dry air is constant. The calibration constant is, however, not strictly constant with height, though it will be treated as such hereafter. The cross section term has a weak temperature dependence that, depending on the bandwidth and blocking of the water vapour interference filter, can vary sufficiently with height to affect the retrieval (Whiteman, 2003). This height variation can be corrected for by modelling combined with knowledge of the nightly temperature profile (say from a radiosonde) or by an empirical correction. For the CEC Lidar measurements the latter option is necessary.

The most important height-dependent corrections that may need to be applied to the raw photocount profiles at the lowest altitudes are corrections for phototube nonlinearity (e.g. pulse pile-up) and incomplete geometric overlap of the transmitted and received beam. At higher altitudes SIN can be an issue (as discussed previously). Ideally one tries to measure these effects to correct the raw measurements. However, due to the limited time available on site during the observing campaigns (about 3 weeks per year) a careful evaluation of these effects was not possible, so it was decided instead to use an empirical correction using the radiosonde measurements of relative humidity, as will be discussed in detail below.

After the atmospheric transmission correction term is applied to the measurements, the calibration constant, $C_{w}$, can be determined. An approximation of this calibration constant is applied to the measurements by including those parameters in the ratio which are known. However, an external source must be used to verify, and possibly correct, this initial value of $C_{w}$.

\subsection{Calibration}

Calibration of lidar water vapour mixing ratios was performed using 11 nights of measurements obtained during the 2008 Canadian Arctic ACE Validation Campaign, using soundings from twice-daily radiosonde flights at 11:15 and 23:15 UT from the Eureka Weather Station.

\subsubsection{Pre-calibration considerations}

Measurements from the radiosondes launched at Eureka are provided by Environment Canada. Both Vaisala RS92 and RS80 model radiosondes were used during the campaigns. The radiosonde relative humidity measurements are converted to mixing ratios, using the radiosonde pressure and temperature measurements and the empirical equation of Hyland and Wexler (1983) to find the appropriate value of the saturation vapour pressure over ice. The Hyland and Wexler (1983) model is considered a "best practice" model to use for converting the radiosonde relative humidity measurements into mixing ratios (Vömel et al., 2007).

Lidar measurements are generally taken from approximately 03:00 to 08:00 UT, which brackets the radiosonde flights. On some nights rapid variations in water vapour content occur in the period between the 2 flights, making these nights less desirable for calibration. However, it is these nights with significant variations in water vapour that show how the lidar measurements can complement the routine radiosonde flights.

Another important consideration for comparison with the sondes is that the lidar takes measurements directly overhead at a fixed location, averaged every $10 \mathrm{~min}$ and $150 \mathrm{~m}$ in altitude, while the radiosonde takes measurements every few seconds as it drifts with the winds. On a given day the balloon may or may not remain in the same air mass as the lidar measurements. This difference is taken into consideration when deciding which radiosonde profiles should be included in the calibration.

\subsubsection{Determination of the system correction and calibration constant}

The calibration was undertaken using nights when the weather was relatively stable, and the individual radiosondes were consistent between both soundings. The calibration based on measurements from the 2008 Canadian Arctic ACE Validation Campaign uses 8 nights of lidar measurements, with 3 nights not included in the calibration due to large changes in water vapour between the two radiosonde flights.

A least-squares procedure is used to find a calibration constant that improves the agreement between the radiosondes and the lidar measurements. The calibration constant is 


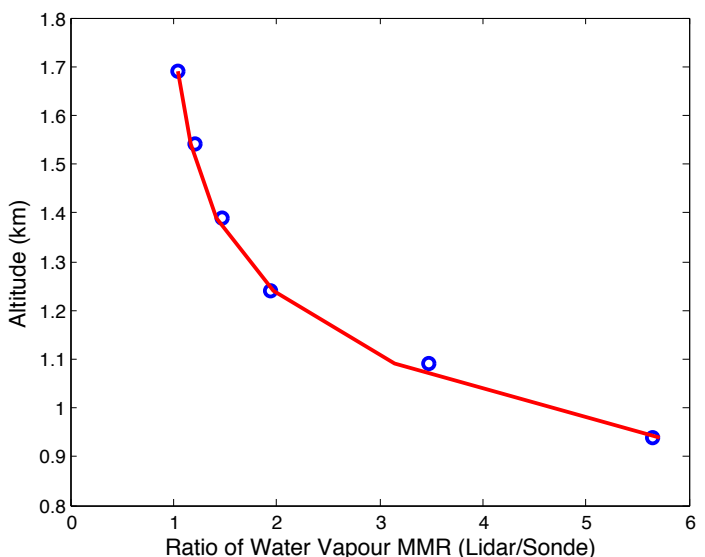

Fig. 1. Ratio of the water vapour mixing ratio for the lidar to the radiosonde for the 2008 season at low altitudes. The uncorrected lidar mixing ratios are 2 to 5 times larger than the radiosonde mixing ratios at the lowest 3 range bins. These differences are due primarily to detector system nonlinearities and incomplete geometric overlap.

found by minimizing the sum of the square of the difference between the radiosonde and lidar water vapour mixing ratio from $0.94 \mathrm{~km}$ to the height where the temperature first reaches $-50^{\circ} \mathrm{C}$. At temperatures below this threshold, the humidity sensors aboard some radiosondes are known to exhibit significant hysteresis effects (Wade, 1994). For this calibration, such threshold temperatures typically occurred at altitudes between 5.6 and $8.0 \mathrm{~km}$, where the statistical uncertainty of the lidar measurements starts to become large.

The minimization to find the fitting factor is

$\min =\sum_{i=1}^{n}\left(\operatorname{Sonde}_{i}-\left(C_{w} \cdot \operatorname{Lidar}_{i}\right)\right)^{2}$

over the specified height range. The calibration constant is then applied to all nights available. Correcting the measurements with this procedure gives excellent agreement in the 1.7 to $4.0 \mathrm{~km}$ region, but not outside this range where height dependent differences between the lidar and the sondes become large.

\subsubsection{Height dependent system corrections}

For a properly calibrated lidar, the calibration constant discussed in the last section should be independent of height over the entire range of useful measurements. Our first attempt at finding $C_{w}$ showed that the deviations from the radiosondes at the lowest and greatest altitudes have a height dependence; thus, system corrections are required at the lowest and greatest heights.

The nitrogen channel was thought to be linear when installed. It was found after analysis of these measurements that this was not the case. Figure 1 shows the ratio of the lidar water vapour mixing ratio to the radiosonde water vapour mixing ratio below $1.7 \mathrm{~km}$. Furthermore, there is a geometric
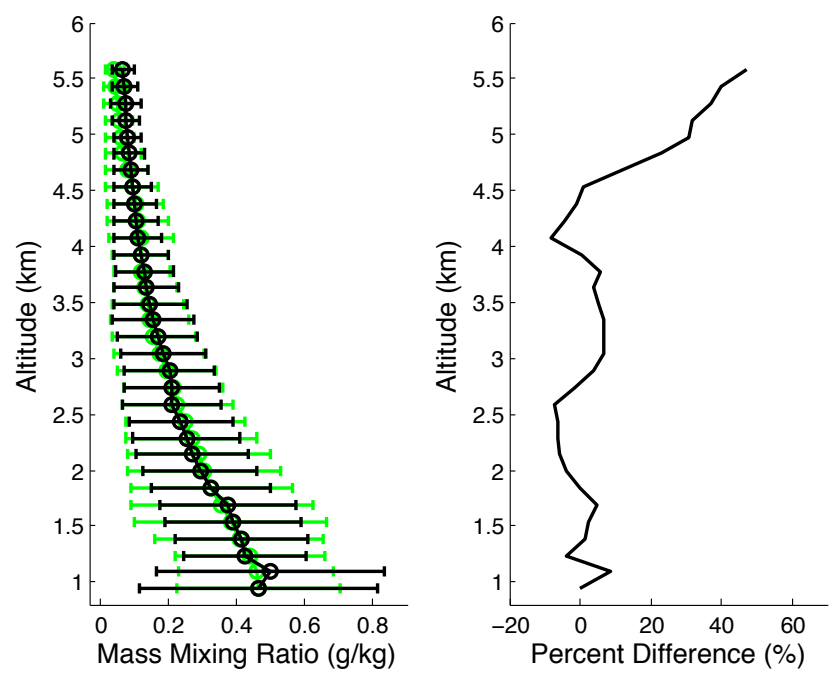

Fig. 2. Comparison of the average 2008 lidar (black) and radiosonde (green) measurements. An exponential correction has been applied to the lidar measurements below $1.7 \mathrm{~km}$. The horizontal bars are the RMS deviations of the measurements.

overlap effect at the lowest altitudes. To empirically account for these effects, an exponential fit to the ratio of the lidar signal to the radiosonde is used to find a correction between 0.94 to $1.69 \mathrm{~km}$ (the lowest 6 range bins). Following this correction, agreement with the radiosondes is much improved, now showing only small differences (less than $10 \%$ ) between the radiosonde and lidar below $4 \mathrm{~km}$ (Fig. 2). However, a disagreement between the data sets is evident above this altitude.

A correction is also required above $4 \mathrm{~km}$. The high-altitude height dependence is not thought to be due to SIN (as previously discussed). Factors which can cause a height dependence include the transmission ratios and temperature effects. Few measurements of aerosol loading at high latitude are incorporated into MODTRAN, though these differences should be small in clear-sky conditions. The transmission ratios assumed are thought to be good to better than a factor of 2. Drift in the water vapour filter with time may account for some of this height-dependent correction, as atmospheric temperature can change with height in this region. We plan to bring the filter back south for testing at the next opportunity. The most likely problem appears to be misalignment of the transmitter and receiver and/or interference from the mechanical chopper causing the spot size from the higher altitudes to not be fully imaged on the phototube. To account for these and possible other variations a correction is determined by fitting a straight line to the ratio of the lidar and radiosonde measurements up to $6 \mathrm{~km}$. The straight line fit (determined separately for each year, see Table 1) has regression coefficients greater than 0.98 . With the high-altitude calibration factor included, the lidar returns now show much better agreement with the radiosondes, with minimal bias. 
Table 1. System corrections and calibration constants for the 2007 to 2009 Canadian Arctic ACE Validation Campaign.

\begin{tabular}{cllc}
\hline Year & Altitude $(\mathrm{km})$ & Instrumental correction & $\begin{array}{c}\text { Calibration } \\
\text { constant }\end{array}$ \\
\hline 2007 & $0.94<z<1.69$ & $0.94+200 \times 10^{-4.6 z}$ & 7.2 \\
& $1.69<z<5.88$ & No correction required & \\
\hline 2008 & $0.94<z<1.69$ & $0.95+604 \times 10^{-5.2 z}$ & 8.1 \\
& $1.69<z<4.53$ & No correction required & \\
& $4.53<z<5.88$ & $0.65 z-1.92$ & \\
\hline 2009 & $0.94<z<1.69$ & $1.0+24 \times 10^{-3.4 z}$ & 7.4 \\
& $1.69<z<3.93$ & No correction required & \\
& $3.93<z<5.88$ & $0.95 z-0.55$ & \\
\hline
\end{tabular}
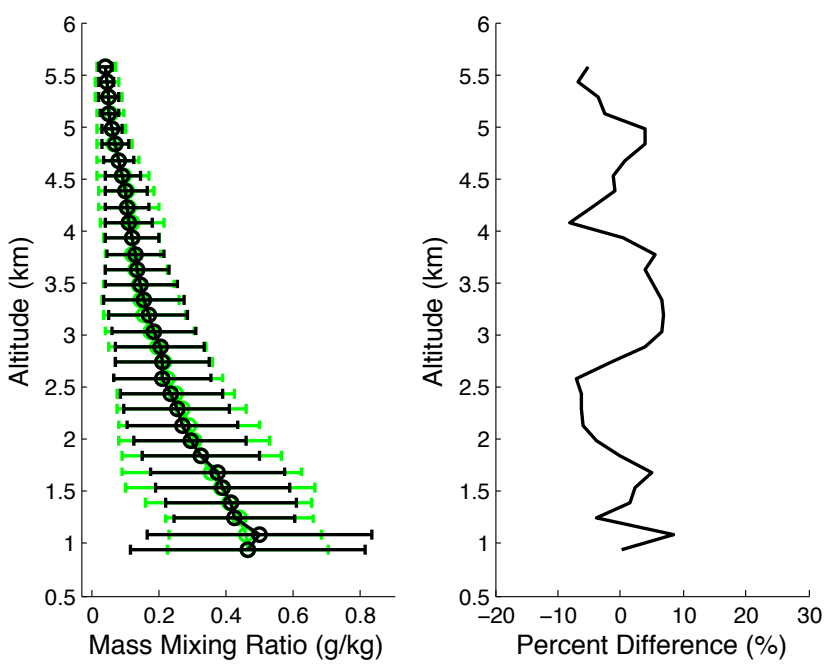

Fig. 3. Comparison of the average 2008 lidar (black) and radiosonde (green) measurements. A linear correction has been applied to the lidar measurements above $4 \mathrm{~km}$, in addition to the low altitude correction shown in Fig. 2. The horizontal bars are the RMS deviations of the measurements. The lidar calibration agrees to within $10 \%$ of the radiosondes with little bias evident.

The least-squares procedure is then performed on the system-corrected measurements to find a final fitting factor, using measurements over the entire altitude range. The result of this procedure gives $C_{w}=8.1$ (Table 1). The average percent difference between lidar and radiosonde measurements is about $5.2 \%$ with small bias (Fig. 3). Agreement is even better in the troposphere, with percent difference less than $10 \%$. The nightly averaged differences between the radiosonde and lidar for individual nights in 2008 using the systematic corrections and final calibration constant are shown in Fig. 4.

Calibration factors were then found for the 2007 and 2009 campaigns in the same manner as for 2008. The calibration factors in 2007 and 2009 are significantly different from 2008, and from each other. This result is not unexpected due to the potential for system parameters and atmospheric

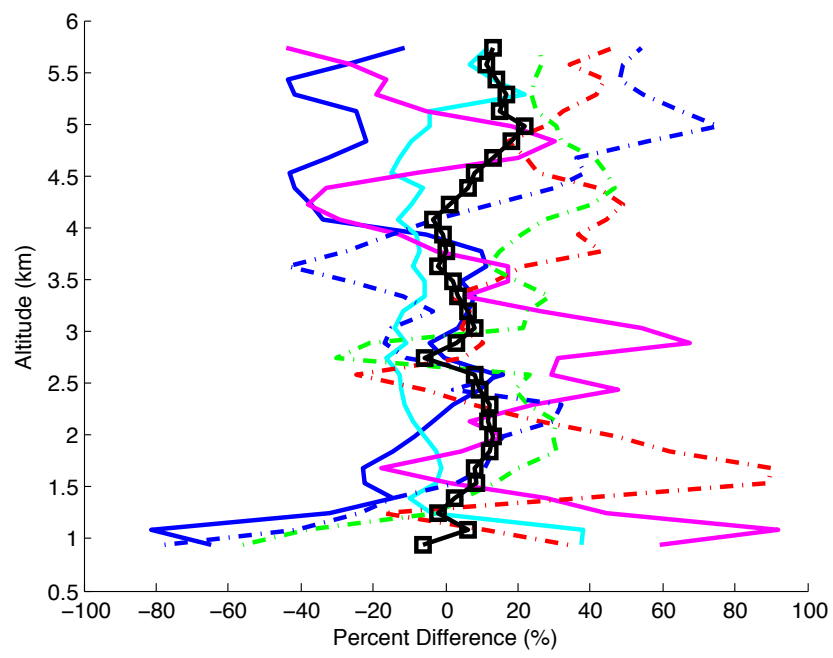

Fig. 4. Percent difference between the nightly averaged lidar measurements minus the radiosonde measurements (coloured lines). The squares show the average of the individual nights. On average the differences between the two instruments is small. On individual nights, above $1.5 \mathrm{~km}$ altitude individual nights can vary as much as $40 \%$ from the average values.

conditions to change from year to year, as the instrument is mothballed between the polar sunrise measurement periods. The major factors influencing the calibration at the lowest heights are any counting nonlinearities in the nitrogen channel and any geometric overlap corrections due to alignment. The significant variations of the corrections at the lowest heights from season to season are primarily due to changes in the system's alignment.

\subsection{Annual calibrations}

Constant corrections are determined for 2007 and 2009 using the same procedures as for 2008 , i.e. a subset of nights chosen each year which showed relatively clear-sky nights and consistent radiosonde measurements. The system correction and calibration constant for each year are given in Table 1. The system correction and calibration constant are similar in shape with a significant difference in magnitude. Trends in the water vapour mixing ratio during polar sunrise were calculated for the 3 periods available (Fig. 5). The nights used in the averages are shown in Table 2. Below $4 \mathrm{~km}$ the largest variability in water vapour mixing ratio was in 2007. In 2009 the variability is smaller at the lowest heights but larger above $4 \mathrm{~km}$ compared to 2007 and 2008. One can speculate that the large variability seen between years is related to changes in the location of the polar vortex from year to year. We are in the process of investigating this possible connection, using a detailed meteorological analysis of the year-to-year dynamics. 


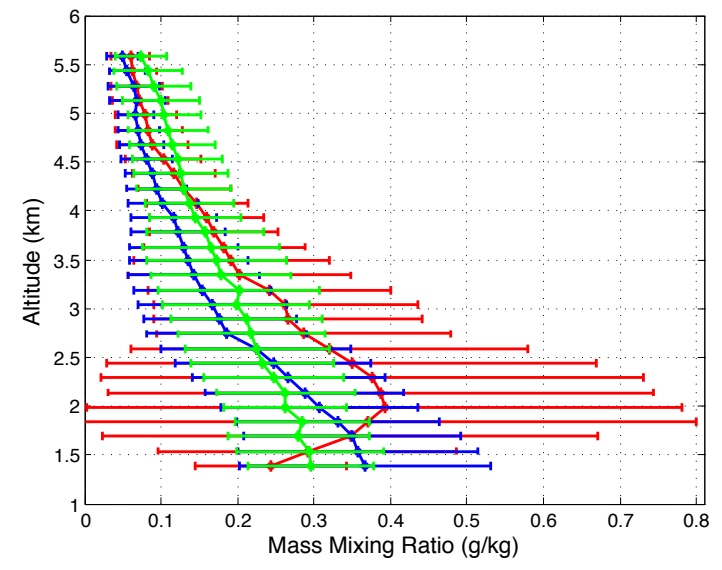

Fig. 5. Yearly variability of water vapour mixing ratio during polar sunrise (February to March) for 2007 (red), 2008 (blue) and 2009 (green). The horizontal bars are the root mean square deviation of the measurement average for the measurement period. The water vapour variability was considerably larger in 2007 compared to the other two years.

\section{Comparisons with the ACE-FTS}

The ACE mission aboard the Canadian SCISAT-1 satellite has been in orbit since August 2003. ACE is comprised of two principal instruments, the ACE-FTS and Measurements of Aerosol Extinction in the Stratosphere and Troposphere Retrieved by Occultation (MAESTRO), which together measure many molecular species of interest in the atmosphere. Both instruments make measurements using a solar occultation method, whereby a reference measurement is taken looking directly at the Sun, then a measurement is taken looking at the Sun through the atmosphere. Bernath et al. (2005) give an overview of the ACE-FTS instrument, while Boone et al. (2005) give a detailed description of the analysis of the ACE-FTS measurements.

The ACE-FTS measurements have a different viewing geometry and height resolution than the lidar measurements. For this comparison the lidar measurements have been coadded in height to more closely match the vertical resolution of ACE-FTS (approximately 3 to $4 \mathrm{~km}$ ). The best set of coincident ACE measurements with the CEC Lidar was during the 2008 campaign, where 4 sets of coincidences were available (Fig. 6). The error bars used for the ACE-FTS and lidar profiles are the RMS deviations associated with the campaign averages (which are much greater than the statistical uncertainties). Though the region of overlap between the measurements is limited, the continuity between the independently calibrated instruments is encouraging.

Figure 7 shows an example of a comparison with a single ACE-FTS overpass. For the four coincidences, the lidar mixing ratios are within $20 \%$ or less of the ACE-FTS retrievals. Since the ACE-FTS measurements are independent of the radiosondes, this comparison gives us confidence in
Table 2. Lidar measurements used in this study.

\begin{tabular}{|c|c|c|c|}
\hline February & 2007 & 2008 & 2009 \\
\hline 8 & & & $\mathrm{o}$ \\
\hline 9 & & & o \\
\hline 10 & & & o \\
\hline 11 & & & o \\
\hline 12 & & & $\mathrm{o}$ \\
\hline 13 & & & \\
\hline 14 & & & \\
\hline 15 & & & \\
\hline 16 & & & o \\
\hline 17 & o & o & o \\
\hline 18 & o & o & o \\
\hline 19 & & & o \\
\hline 20 & & & \\
\hline 21 & o & & o \\
\hline 22 & o & & o \\
\hline 23 & & o & $\mathrm{o}$ \\
\hline 24 & & o & o \\
\hline 25 & & $\mathrm{x}$ & o \\
\hline 26 & & & \\
\hline 27 & o & & \\
\hline 28 & & o & \\
\hline 29 & & o & \\
\hline March & 2007 & 2008 & 2009 \\
\hline 1 & $\mathrm{O}$ & $\mathrm{O}$ & o \\
\hline 2 & & o & o \\
\hline 3 & & o & o \\
\hline 4 & o & o & \\
\hline 5 & & & o \\
\hline 6 & o & & o \\
\hline
\end{tabular}

An "o" for a given date indicates measurements are included in the averages. An " $x$ " indicates that measurements exist on the date but were not of sufficient quality (primarily due to deteriorating weather over the night) to use in the average.

the empirically determined corrections and calibration of the CEC Lidar.

\section{Spatial-temporal coverage of the CEC Lidar}

If the CEC Lidar could only take nightly averaged profiles, it would not complement the twice-daily radiosonde flights. However, even at high latitudes during the polar sunrise period, the tropospheric water vapour can be highly variable on a time scale much shorter than the $12 \mathrm{~h}$ between radiosonde flights. To demonstrate these differences, consider the water vapour mixing ratio on two nights, shown at a spatial resolution of $150 \mathrm{~m}$ and a temporal resolution of $10 \mathrm{~min}$ in Figs. 8 and 9. The upper altitude limit of the contours is set at the height where statistical uncertainty for an individual ten-minute profile first reaches $10 \%$. 


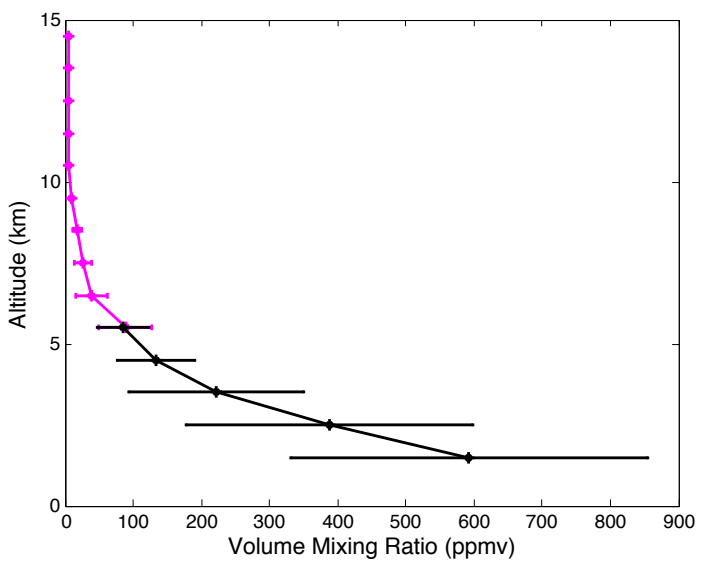

Fig. 6. Comparison of water vapour mixing ratio measurements made by the CEC Lidar (black) and ACE-FTS (magenta) in 2008. The ACE-FTS profile is the average of all measurements within $200 \mathrm{~km}$ (measured from the $30 \mathrm{~km}$ point of the ACE-FTS occultation and the CEC Lidar) made during the Canadian Arctic ACE Validation Campaign period. The lidar profile is the average of the coincident nights. The horizontal bars indicate the RMS deviation of the average.

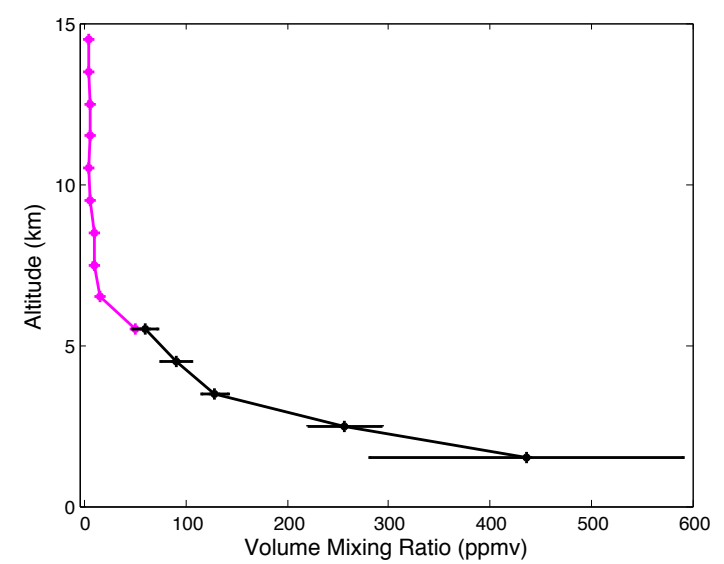

Fig. 7. Comparison of water vapour mixing ratio measurements made by the CEC Lidar (black) and ACE-FTS (magenta). The lidar profile is the average from 03:40 to 08:50 UT on the night of 28 February 2008. The ACE-FTS profile is for measurements taken at 20:40 UT near Eureka on 27 February 2008.

On 28 February 2008 there is very little change of water vapour over the night, so the RMS variation of the individual profiles is small relative to most of the other 39 nights of measurements. However, even on this night the water vapour above $3 \mathrm{~km}$ altitude increases 25 to $50 \%$ over $2 \mathrm{~h}$.

An example of a night with higher variability is 18 February 2007. On 18 February 2007 the water vapour mixing ratio almost doubles in a period of only about $30 \mathrm{~min}$ in a region less than about $1 \mathrm{~km}$ thickness. Note this region of enhanced water vapour becomes narrower in vertical extent by the end of measurements. Routine radiosonde measurements could

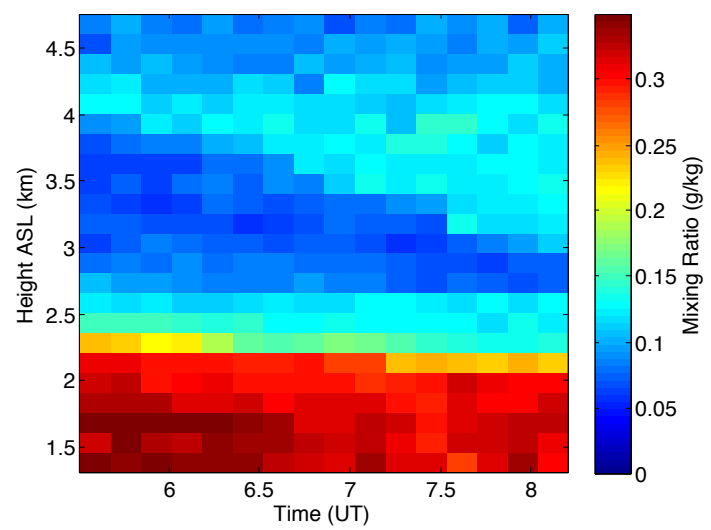

Fig. 8. Contour plot at a spatial resolution of $150 \mathrm{~m}$ and a temporal resolution of $10 \mathrm{~min}$ for measurements on the night of 28 February 2008. This night was chosen as an example of a period of relatively small changes in water vapour mixing ratio compared to most of the other 39 nights available. However, even on this night the water vapour increases 25 to $50 \%$ above $3 \mathrm{~km}$ altitude.

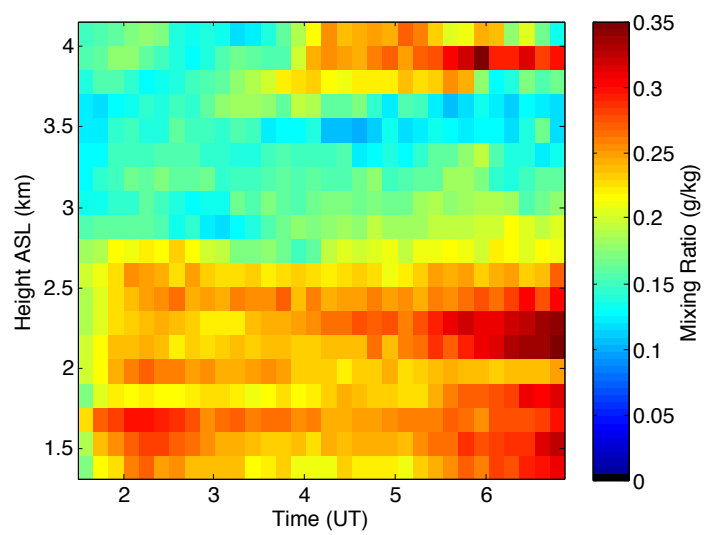

Fig. 9. Contour plot at a spatial resolution of $150 \mathrm{~m}$ and a temporal resolution of $10 \mathrm{~min}$ for measurements on the night of 18 February 2007. This night was chosen as an example of a period with a rapid increase in the water vapour mixing ratio after 04:00 UT.

miss features like this. Hence, having the radiosondes and lidar measurements agree when the changes over $12 \mathrm{~h}$ are small does not mean the lidar measurements are not of value: rather it means the lidar measurements can be used to track rapid changes, such as those shown in Fig. 9, that could occur between radiosonde flights. Of the 39 nights available for this study only about $25 \%$ of them were similar to 28 February 2008. On most nights there were significant changes in the tropospheric water vapour with time. 


\section{Conclusions}

A water vapour system correction and calibration constant are determined for the CEC Lidar. For this calibration, a comparison was done to measurements made by radiosonde balloons launched twice daily from the nearby Eureka Weather Station. The calibration involves a system (height-dependent) correction, as well as a constant calibration factor determined by least-squares fitting on nights with consistent radiosonde measurements. The calibration is tested on lidar measurements from 2007 and 2009 for interannual consistency. Agreement with the radiosondes is poor in 2007 and 2009 using the 2008 calibration, demonstrating that annual calibration efforts are necessary. Statistical uncertainty limits nightly-averaged water vapour mixing ratio profiles to about $6 \mathrm{~km}$ altitude. Nightly contours at $10 \mathrm{~min}$ time resolution and $150 \mathrm{~m}$ vertical resolution reach altitudes around $5 \mathrm{~km}$.

Limitations of the calibration technique used include the lack of both temporal and spatial coincidence between the lidar and radiosonde measurements, as well as the inability of the radiosondes to make reliable humidity measurements in the upper troposphere. Use of balloon-borne frost-point hygrometers would help with calibration of water vapour mixing ratios in the tropopause region. Furthermore, techniques are being developed to improve long-term calibration of water vapour lidar systems, including white light calibrations (Sherlock et al., 1999), a hybrid approach involving both radiosondes and a calibration lamp (Leblanc and McDermid, 2008), as well as a first-principle calibration using lamps which scan the entire system field of view, eliminating the need to compare to other independent water vapour measurements (Venable et al., 2011). Such methods will be considered for adoption in future CEC Lidar measurements.

Acknowledgements. The authors would like to thank the CANDAC and PEARL staff and the PEARL operators for assistance in instrument preparation, maintenance and data collection throughout the numerous challenges involved with working in the North. We would also like to thank the Referees for their many helpful suggestions.

The Atmospheric Chemistry Experiment (ACE), also known as SCISAT, is a Canadian-led mission mainly supported by the Canadian Space Agency and the Natural Sciences and Engineering Research Council of Canada.

The Canadian Arctic ACE Validation Campaign project has been supported by the Canadian Space Agency (CSA), Environment Canada (EC), the Natural Sciences and Engineering Research Council (NSERC) of Canada, the Northern Scientific Training Program and the Centre for Global Change Science at the University of Toronto. Logistical and on-site technical support for the 2006-2009 campaigns was provided by the Canadian Network for the Detection of Atmospheric Change (CANDAC).

CANDAC and PEARL research was supported by the Canadian Foundation for Innovation, the Ontario Innovation Trust, the Ontario Research Fund, the Canadian Foundation for Climate and
Atmospheric Sciences (CFCAS), the Natural Sciences and Engineering Council (NSERC), Environment Canada, the Polar Continental Shelf Project (PCSP), the Canadian International Polar Year Program, and the Canadian Space Agency (CSA).

A. Moss and E. McCullough thank the NSERC CREATE Training Program in Arctic Atmospheric Science for their support.

Edited by: H. Worden

\section{References}

Anderson, G. P., Chetwynd Jr., J. H., Theriault, J. M., Acharya, P. K., Berk, A., Robertson, D. C., Kneizys, F. X., Hoke, M. L., Abreu, L. W., and Shettle, E. P.: MODTRAN2: Suitability for remote sensing, in: Optical Engineering and Photonics in Aerospace Sensing, International Society for Optics and Photonics, Bellingham, Washington, USA, 514-525, 1993.

Bernath, P. F., McElroy, C. T., Abrams, M. C., Boone, C. D., Butler, M., Camy-Peyret, C., Carleer, M., Clerbaux, C., Coheur, P. F., Colin, R., DeCola, P., Bernath, P. F., McElroy, C. T., Abrams, M. C., Boone, C. D., Butler, M., Camy-Peyret, C., Carleer, M., Clerbaux, C., Coheur, P. F., Colin, R., DeCola, P., DeMaziere, M., Drummond, J. R., Dufour, D., Evans, W., Fast, H., Fussen, D., Gilbert, K., Jennings, D. E., Llewellyn, E. J., Lowe, R. P., Mahieu, E., McConnell, J. C., McHugh, M., McLeod, S. D., Michaud, R., Midwinter, C., Nassar, R., Nichitiu, F., Nowlan, C., Rinsland, C. P., Rochon, Y. J., Rowlands, N., Semeniuk, K., Simon, P., Skelton, R., Sloan, J. J., Soucy, M. A., Strong, K., Tremblay, P., Turnbull, D., Walker, K. A., Walkty, I., Wardle, D. A., Wehrle, V., Zander, R., and Zou, J.: Atmospheric Chemistry Experiment (ACE): Mission overview, Geophys. Res. Lett., 32, L15S01, doi:10.1029/2005GL022386, 2005.

Boone, C., Nassar, R., Walker, K., Rochon, Y., McLeod, S., Rinsland, C., and Bernath, P.: Retrievals for the atmospheric chemistry experiment Fourier-transform spectrometer, Appl. Optics, 44, 7218-7231, 2005.

Carswell, A., Pal, S., and Steinbrecht, W.: Lidar measurements of the middle atmosphere, Can. J. Phys., 69, 1076-1086, 1991.

Hyland, R. W. and Wexler, A.: Formulations for the thermodynamic properties of the saturated phases of $\mathrm{H}_{2} \mathrm{O}$ from $173.15 \mathrm{~K}$ to $473.15 \mathrm{~K}$, Trans. Am. Soc. Heat. Refrig. Air-Condition.Eng., 89, 500-519, 2005.

Leblanc, T. and McDermid, I. S.: Accuracy of Raman lidar water vapor calibration and its applicability to long-term measurements, Appl. Optics, 47, 5592-5603, 2008.

Melfi, S. H., Lawrence, J. D., and McCormick, M. P.: Observation of Raman Scattering by Water Vapor in Atmosphere, Appl. Phys. Lett., 15, 295-297, 1969.

Pal, S., Carswell, A., Bird, J., Donovan, D., Duck, T., and Whiteway, J.: Lidar measurements of the stratosphere at the Eureka and Toronto NDSC stations, in: Proceedings, edited by: Pal, S. R., York Univ., Inst. Space \& Terr. Sci., N York, Canada, 28-39, 1996.

Sherlock, V., Hauchecorne, A., and Lenoble, J.: Methodology for the Independent Calibration of Raman Backscatter Water-Vapor Lidar Systems, Appl. Optics, 38, 5816-5837, 1999.

Steinbrecht, W.: Lidar measurements of ozone, aerosol and temperature in the stratosphere, PhD Thesis, York University, 1994. 
Venable, D. D., Whiteman, D. N., Calhoun, M. N., Dirisu, A. O., Connell, R. M., and Landulfo, E.: Lamp mapping technique for independent determination of the water vapor mixing ratio calibration factor for a Raman lidar system, Appl. Optics, 50, 46224632, 2011.

Vömel, H., Selkirk, H., Miloshevich, L., Valverde-Canossa, J., Valdés, J., Kyrö, E., Kivi, R., Stolz, W., Peng, G., and Diaz, J. A.: Radiation Dry Bias of the Vaisala RS92 Humidity Sensor, J. Atmos. Ocean. Tech., 24, 953-963, 2007.
Wade, C. G.: An Evaluation of Problems Affecting the Measurement of Low Relative-Humidity on the United-States Radiosonde, J. Atmos. Ocean. Tech., 11, 687-700, 1994.

Whiteman, D. N.: Examination of the traditional Raman lidar technique, 1. Evaluating the temperature-dependent lidar equations, Appl. Optics, 42, 2571-2592, 2003.

Whiteman, D. N., Melfi, S., and Ferrare, R.: Raman Lidar System For The Measurement Of Water-Vapor And Aerosols In The Earths Atmosphere, Appl. Optics, 31, 3068-3082, 1992. 